BOLLES, R. C., \& GROSSEN, N, E Function of the $C S$ in shuttle-box avoidance learning by rats. Journal of Comparative \& Physiological Psychology, $1970,70,165-169$.

BOLLES, R. C.. STOKES, L. W., \& YOUNGER, M. S. Does CS termination reinforce avoidance behavior? Journal of Comparative \& Physiological Psychology, $1966,62,201-207$

FLEMING, R. A., \& HERSHMAN, R. L The application of information theory to differential conditioning. Paper presented at the meeting of the Psychonomic Society, St. Louis, 1969.
HERRNSTEIN, R.J. Method and theory in the study of avoidance. Psychological Review, 1969, 76, 49-69.

KNAPP, R. K.. KAUSE, R. H., \& PERKINS C. C., JR. Immediate vs delayed shock in T-maze performanee. Journal of Experimental Psychology, 1959, 58 . Experim

LOCKARD, J. S. Choice of a warning signal or no warning signal in an unavoidable shock situation. Journal of Comparative \& Physiological Psychology, 1963,56. $526-530$.

RESCORLA, R. A. Probability of shock in the presence and absence of $C S$ in fear conditioning. Journal of Comparative \& Physiological Psychology, 1968, 66, 1-5.

\section{Preference for mirror image stimulation in goldfish (Carassius auratus)}

\author{
GORDON G. GALLUP, JR., and JOHN Y. HESS \\ Tulane University, New Orleans, La. 70118
}

Ten goldfish, given a continuous choice between orienting toward a mirror or another conspecific behind Plexiglas, exhibited a distinct preference for mirror-image stimulation. Moreover, the ratio of time spent in association with the mirror plus a target fish to time in the neutral zone showed a tendency to increase as a function of the amount of social deprivation imposed prior to testing. The results were discussed in terms of implications for theories that attribute the appetitive properties of mirror confrontation to the fact that it elicits an aggressive display.

It has been demonstrated repeatedly for a number of animals that visual access to a mirror, or what is called mirror-image stimulation (MIS), can serve as a reinforcement for learning to make a variety of instrumental responses (e.g., MacLean, 1964; Thompson \& Sturm, 1965). More recently, evidence has been obtained which shows that at least for some species of fish, birds, and primates, there is a preference for watching their own reflections in mirrors over watching a conspecific behind glass (Baenninger, 1966; Gallup \& Capper, 1970; Gallup \& McClure, 1971). Although many animals respond socially to mirrors, as if the reflection represented another animal (Gallup, 1968), a preference for the reflection implies that MIS represents an atypical form of social stimulation and may impose limitations on the use of mirrors in animal social experimentation.

The present study represents an attempt to assess possible preferences for MIS in goldfish. Furthermore, it has been suggested (e.g., Hogan, 1967) that the appetitive properties of MIS derive primarily from the fact that such stimulation typically elicits an aggressive display. Since goldfish do not ordinarily show stereotyped aggressive displays in response to seeing their reflections, a preference for mirrors would have to be attributable to something other than aggressive motivation.

\section{SUBJECTS}

The Ss consisted of 10 experimentally naive goldfish (Carassius auratus) obtained from a local supplier; they ranged from approximately 5 to $8 \mathrm{~cm}$ in length at the beginning of the experiment. During the course of the experiment, all Ss were maintained on tubifex worms. As far as could be determined, none of the fish had ever been previously exposed to fabricated mirrors.

\section{APPARATUS}

The apparatus consisted of a 10-gal aquarium fitted with Plexiglas partitions which provided for a $.12-\mathrm{m}$-wide $\times .51-\mathrm{m}$-long underwater alley. On the outside of the last $.12 \mathrm{~m}$ of one $.51-\mathrm{m}$ wall was a $.12 \times .12 \mathrm{~m}$ glass mirror. Attached to the outside of the same wall at the other end of the alley was a $.12-\mathrm{m}$-square Plexiglas container for temporarily housing a target or stimulus fish. By placing the stimuli on the outside of the last $.12 \mathrm{~m}$ of either end of one wall, rather than at opposing ends of the alley, a fish would not be able to view both stimuli simultaneously from any position in the alley. In addition, the alley was constructed such that the position of the mirror and target fish container could be reversed as a control for position preferences.

Except for the last $.12 \mathrm{~m}$ of either end of the wall separating the alley from the mirror and stimulus fish container, the inside of the entire alley was painted white in an attempt to eliminate extraneous extraalley cues. The alley and the target container were filled with dechlorinated tap water to a height of $.11 \mathrm{~m}$, and water temperature during testing was maintained at approximately $74^{\circ} \mathrm{F}$.

Electric timers activated by single-throw switches were used to record the amount of time spent by a fish in different portions of the alley. PROCEDURE

The Ss were divided randomly into two groups of five fish and were housed in separate aquaria. After adaptation to the housing conditions, each group was then placed into the alley for 3 days to adapt them to the experimental situation. Both the mirror and a stimulus fish in the Plexiglas container were present during the adaptation period.

Preference testing was initiated by placing an individual fish in the alley for $60 \mathrm{~min}$. Three 10-min observations were made after the first 10,30 , and $50 \mathrm{~min}$ of the 1 -h period, during which time the number of seconds spent in front of the mirror and in front of the target fish were recorded.

The second phase of the experiment represented a preliminary attempt to assess the effect of social-deprivation on visual preferences. Seven days after all Ss had been tested according to the above regime, half of the fish were isolated from each other in opaque individual containers for $30 \mathrm{~min}$ before receiving an additional $60-\mathrm{min}$ trial. The remaining five fish were isolated for $120 \mathrm{~min}$ prior to receiving a second trial.

\section{RESULTS}

The average amount of time spent in front of the mirror, the target fish, and in the neutral portion of the alley was summed over the three $10-\mathrm{min}$ recording periods and is depicted in Fig. 1. As can be seen, the fish spent roughly three times more time in front of the mirror than in front of the target fish. The difference between time spent in the mirror zone vs the target fish area was analyzed by computing a $t$ test for related measures and proved to be statistically significant $(t=4.33, \mathrm{df}=9, \mathrm{p}<.01)$. As a further check on these differences, a sign test run on the same comparison also yielded evidence of a 
significant preference $(p=.02)$ for MIS over visual access to a stimulus fish.

During testing, the positions of the mirror and stimulus fish were reversed for 3 of the 10 fish as a control for possible position preferences. The mean time spent in the vicinity of MIS as opposed to the target fish was $1,324.3 \mathrm{sec}$ vs $295.3 \mathrm{sec}$ for the $3 \mathrm{fish}$ given the reversed positions, as compared to $1,236.0 \mathrm{sec}$ MIS time and $449.0 \mathrm{sec}$ stimulus fish time for the remaining 7 fish. Thus, the apparent preference for MIS would appear unconfounded by possible position preferences or extraalley cues.

Figure 2 shows the effect of varying periods of social isolation on the ratio of social time (mirror plus target fish) to neutral zone time. Following social deprivation, the amount of time spent in front of the mirror and the target fish increases, with the relative preference for MIS remaining about the same, while time in the middle portion of the alley shows a consistent decrease with increasing deprivation. After $2 \mathrm{~h}$ of social deprivation, the ratio of social to neutral time is over 2.75 times that obtained for nondeprived fish. A statistical analysis was not performed on the deprivation data due to the fact that the fish in the $30-\mathrm{min}$ and $2-\mathrm{h}$ conditions jointly contribute to the data protrayed in the $0-h$ condition, and therefore the deprivation effect should be taken as being only suggestive.

\section{DISCUSSION}

The present data augment those of previous investigators in showing that some animals prefer MIS over visual access to a conspecific, with the goldfish spending 3.13 times more time in front of a mirror than in the vicinity of another fish. Moreover, the absolute preference for social stimulation appeared to increase with periods of increasing social isolation.

A number of investigators (Baenninger, 1970; Hogan, 1967; Melvin \& Anson, 1970; Thompson, 1963, 1964), using male Siamese fighting fish (Betta splendens), paradise fish (Macropodus opercularis), or fighting cocks, have suggested that the appetitive properties of MIS are related to the fact that it typically produces an aggressive display by the animal confronted with such stimulation. The implication is that the aggressive response is what has appetitive properties for these animals and not the mirror reflection per se.

However, unlike Bettas, paradise fish, and fighting cocks, goldfish do not exhibit obvious aggressive responses when confronted with mirrors or conspecifics. Yet in the present study these animals show a

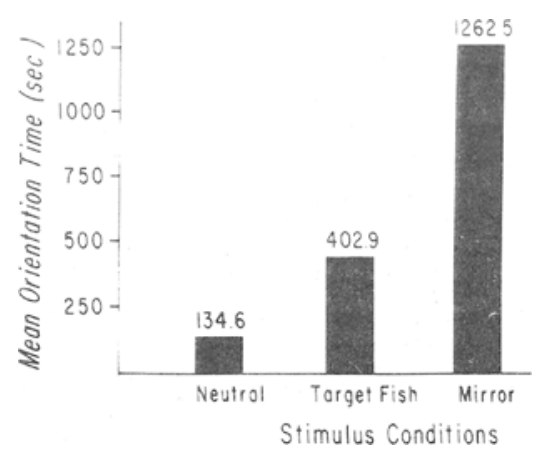

Fig. 1. Time spent in the vincinity of the three different stimulus conditions a veraged over three $10-\mathrm{min}$ recording sessions.

persistent preference for MIS which appears to equal or exceed that reported for Siamese fighting fish (Baenninger, 1966). Gallup \& Capper (1970) reported a similar finding for parakeets (Melopsittacus undulatus), who also showed little or no evidence of aggressive behavior to mirrors.

Since the reflection always counters every movement made by an observer, MIS would seem to constitute an atypical form of social stimulation, but one which apparently serves to maximize stimulation for further interaction. The fact that such stimulation would be expected to contrast with previous social experiences, and therefore contain a novelty component, might be one way to account for a mirror preference.

Another possibility relates to the outcome of natural social encounters. In front of a mirror, the normal reciprocal exchange of social responses, as well as the ultimate outcome, is clearly upset, such that the observer may perseverate by way of trying to approximate a more natural exchange (Gallup \& Capper, 1970). The social behavior of fish and

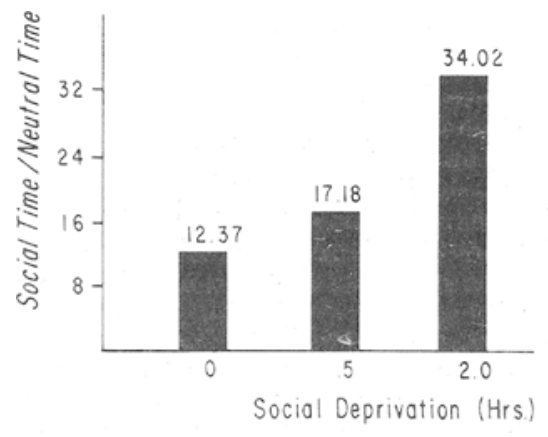

Fig. 2. Ratio of time spent in the presence of social stimuli (mirror plus stimulus fish) to time in the neutral portion of the alley as a function of varying periods of social isolation. birds may be so stereotyped and rigidly preprogrammed that reciprocal stimulation from a conspecific is needed to progress through the normal chain of events to some end point, while in the absence of such an exchange the animal may be bound to the situation. For example, the mirror image never assumes a submissive posture in response to an aggressive display by the $O$, but the achievement of some such outcome may be necessary to exit from the loop or terminate the social episode. In support of this interpretation, Baenninger, Bergman, \& Baenninger (1969) have found that for Bettas a mirror is a more effective stimulus for eliciting aggressive displays than is another live male.

Therefore, while it remains possible that the aggressive motivation elicited by MIS in some species may contribute to its incentive value, a variety of other interpretations still exist. Moreover, elicited aggression seems an insufficient basis for the appetitive properties of MIS which obtain for species showing little agonistic behavior to mirrors.

\section{REFERENCES}

BAENNINGER, R. Waning of aggressive motivation in Betta splendens. Psychonomic Science, 1966, 4, 241-242.

BAENNINGER, R. Visual reinforcement, habituation, and prior social experience of Siamese fighting fish. Journal of Comparative \& Physiological Psychology, $1970,71,1-5$.

BAENNINGER, L.. BERGMAN, M., \& BAENNINGER, R. Aggressive motivation in Betta splendens: Replication and extension. Psychonomic Science, 1969, $16,260-261$.

GALLUP, G. G., JR, Mirror-image stimulation. Psychological Bulletin, 1968. 70, 782-793.

GALLUP, G. G., Jr., \& CAPPER, S. A. Preference for mirror-image stimulation in finches (Posser domesticus domesticus) and parakeets (Melopsittacus undulatus). A nimal Behaviour, 1970, 18,621-624.

GALLUP, G. G., JR., \& McCLURE, M. K. Preference for mirror-image stimulation in differentially reared rhesus monkeys. Journal of Comparative \& Physiological Psychology, 1971, in press.

HOGAN, J. A. Fighting and reinforcement in the Siamese fighting fish Betto splendens). Journal of Comparative \& Physiological Psychology, 1967, 64, 356-359.

MacLEAN, P. D. Mirror display in the squirrel monkey. Science, 1964, 146, 950-952.

MELVIN, K. B., \& ANSON, J, E, Image-induced aggressive display: Reinforcement in the paradise tish. The Psychological Record, 1970, 20, 225-228.

THOMPSON. T. I. Visual reinforcement in Siamese fighting fish. Science, 1963, 141, $55-57$.

THOMPSON, T. I. Visual reinforcement in fighting cocks. Journal of the Experimental Analysis of Behavior, 1964, 7, $45 \cdot 49$.

THOMPSON, T. I., \& STURM, T. $V$ isual-reinforcer color and operant behavior in Siamese fighting fish. Journal of the Experimental Analysis of Behavior. $1965,8,341-346$. 